\title{
REFLEXÃO SOBRE ATUAÇÃO NO PRONTO SOCORRO DO HOSPITAL MUNICIPAL DO CAMPO LIMPO (HMCL) NO CONTEXTO DE URGÊNCIA E EMERGÊNCIA
}

\author{
Léa Constantino ${ }^{1}$ \\ 1. Serviço de Psicologia \\ Hospital Municipal Fernando Mauro Pires da Rocha (HMCL) -São Paulo- SP. \\ E-mail: leaconstantino@ig.com.br
}

\section{Resumo}

Este estudo pretende refletir sobre a atuação do psicólogo e da necessidade da flexibilidade do atendimento psicológico no Pronto Socorro do HMCL, implantado em janeiro de 2010 pela Coordenação do Serviço de Psicologia, devido à necessidade da inserção deste profissional na equipe multiprofissional, buscando agregar um atendimento humanizado, integrando paciente/família e equipe no ambiente de urgência e emergência médicas, considerando que a internação na emergência desestabiliza a família, desencadeando sofrimento psíquico que diante das situações inesperadas e imprevisíveis, causam inseguranças, incertezas, medo da $\mathrm{s}$ doenças, dor e da morte.

Palavras Chave: Atendimento psicológico; sofrimento psíquico; emergência.

\section{Introdução}

O pronto socorro é uma das portas de entrada do paciente no hospital. Destina-se a receber pessoas, necessitando de um pronto atendimento com ou sem risco de morte, não apenas com a dor física, mas também, com a dor psíquica e sua subjetividade. O PS passou a ser um serviço que absorve todos os problemas de saúde e sociais refletindo a

\footnotetext{
Referência:

Constantino, Léa. Reflexão sobre Atuação no Pronto Socorro do Hospital Municipal do Campo Limpo (HMCL) no Contexto de Urgência e Emergência. In: Anais da V Jornada de Psicologia no Hospital Municipal do Campo Limpo [= Blucher Medical Proceedings, vol.1, num.6]. São Paulo: Editora Blucher, 2015.
}

DOI $10.5151 /$ medpro-5jphmcl-003 
dificuldade de organização e resolutividade da rede pública de saúde, principalmente da atenção primária.

\section{O psicólogo e a situação de emergência}

Quando chega ao PS o paciente se vê imerso numa situação de desamparo e de certa forma, perde sua dignidade quando deixa sua posição de sujeito, passando a ser objeto de intervenção. É submetido a procedimentos médicos, que embora visem sua melhora, podem adquirir um caráter ameaçador e invasivo. Assim, ele vive um momento de perda de referencial, que é acompanhada por vivências de isolamento, abandono e rompimento de laços: Afetivos, profissionais e sociais.

O psicólogo tenta, na medida do possível, resguardar os pacientes e familiares. Os atendimentos são breves, focais e procuram "resgatar" o equilíbrio emocional, a partir do oferecimento de uma escuta que permita a explicitação do sofrimento.

$\mathrm{O}$ acolhimento visa à escuta, a valorização das queixas do paciente/família, a identificação das suas necessidades, o respeito às diferenças.

A intervenção do psicólogo pode auxiliar o tratamento médico, na medida em que sensibiliza a equipe para aspectos emocionais, que dificultam a comunicação com o paciente, facilita a implicação do paciente em seu tratamento, a reabilitação e oferece um acolhimento para a família. A Intervenção psicológica contribui para melhorar a qualidade de trabalho de equipe, intervindo junto ao paciente e seu familiar.

\section{Conclusões}

$\mathrm{O}$ atendimento psicológico procura resgatar e reorganizar o equilíbrio emocional do paciente/família permite a explicitação de conflitos inconscientes, através da escuta e a intermediação das relações entre paciente, família e equipe de saúde, visa auxiliar o trabalho em equipe e integral, somando saberes, tornando a interdisciplinaridade uma ferramenta de otimização das atividades, alcançando assim, a eficácia dos serviços no atendimento de urgência e emergência. 


\section{Referências Bibliográficas:}

1. CAMON, V.A.A. (2002) Breve reflexão sobre a postura do profissional da saúde diante da doença e do doente. In: Camon, V.A.A. Urgências psicológicas no hospital, São Paulo. Ed. Pioneira Thompson learning, 41-60.

2. Coppe, A.A. F, \& Miranda, E.M.F. (2002). O psicólogo diante da urgência no pronto socorro. In. V. A. Angerami-Camon (Org.), Urgência psicológicas no hospital (pp. 61-80). São Paulo Pioneira. 